\title{
Salmonella Typhimurium induces SPI-1 and SPI-2 regulated and strain dependent downregulation of MHC II expression on porcine alveolar macrophages
}

\author{
Alexander Van Parys ${ }^{*}$, Filip Boyen, Elin Verbrugghe, Bregje Leyman, Flahou Bram, Freddy Haesebrouck ${ }^{\dagger}$ \\ and Frank Pasmans ${ }^{\dagger}$
}

\begin{abstract}
Foodborne salmonellosis is one of the most important bacterial zoonotic diseases worldwide. Salmonella Typhimurium is the serovar most frequently isolated from persistently infected slaughter pigs in Europe. Circumvention of the host's immune system by Salmonella might contribute to persistent infection of pigs. In the present study, we found that Salmonella Typhimurium strain 112910a specifically downregulated MHC II, but not MHC I, expression on porcine alveolar macrophages in a Salmonella pathogenicity island (SPI)-1 and SPI-2 dependent way. Salmonella induced downregulation of MHC II expression and intracellular proliferation of Salmonella in macrophages were significantly impaired after opsonization with Salmonella specific antibodies prior to inoculation. Furthermore, the capacity to downregulate MHC II expression on macrophages differed significantly among Salmonella strains, independently of strain specific differences in invasion capacity, Salmonella induced cytotoxicity and altered macrophage activation status. The fact that strain specific differences in MHC I downregulation did not correlate with the extent of in vitro SPI-1 or SPI-2 gene expression indicates that other factors are involved in MHC II downregulation as well. Since Salmonella strain dependent interference with the pig's immune response through downregulation of $\mathrm{MHC} \|$ expression might indicate that certain Salmonella strains are more likely to escape serological detection, our findings are of major interest for Salmonella monitoring programs primarily based on serology.
\end{abstract}

\section{Introduction}

Nontyphoidal salmonellosis is one of the most important bacterial zoonotic diseases, yearly resulting in an estimated 155000 deaths worldwide [1]. In European countries, Salmonella enterica subspecies enterica serovar Typhimurium (Salmonella Typhimurium) is the serovar most frequently isolated from slaughter pigs [2]. Pig carcass contamination with Salmonella Typhimurium can largely be attributed to persistently infected pigs [3]. In most cases, the bacterium will asymptomatically colonize pigs, resulting in a so called "carrier status" $[4,5]$. In the past, Salmonella infections in pig herds have

\footnotetext{
* Correspondence: Alexander.vanparys@ugent.be

${ }^{\dagger}$ Equal contributors

Ghent University, Faculty of Veterinary Medicine, Department of Pathology, Bacteriology and Avian Diseases, Salisburylaan 133, 9820, Merelbeke, Belgium
}

traditionally been diagnosed by culturing intestinal or faecal samples [6]. Because pigs only excrete high numbers of bacteria during the acute phase of infection and then become intermittently excreting carriers, serological surveillance is perceived as a practical (highthroughput) and cost-effective alternative for monitoring Salmonella infection in pig herds [6-9].

After infection by a pathogen, the host's immune system will respond through an innate and a subsequent adaptive immune response. The success of many persisting pathogens relies on their ability to resist, circumvent or counteract the host's innate and/or adaptive immune responses. Several bacteria and viruses have developed pathways interfering with antigen presentation by the host's immune system, for example by inhibition of $\mathrm{MHC}$ expression and antigen presentation through 
distinct mechanisms [10-12]. The Salmonella genome contains several Salmonella pathogenicity islands (SPIs'), clusters of genes that encode virulence factors involved in different stages of Salmonella pathogenicity [13]. SPI-2, encoding a type III secretion system, plays a role in Salmonella-mediated downregulation of cell surface MHC class II expression in human cell lines by recruiting membrane for the Salmonella containing vacuole [12]. However, Salmonella exhibits host specific behaviour and no data are available yet on this phenomenon in pigs. In addition, it is not known whether different Salmonella strains might be able to interfere differentially with the MHC II expression pathway in porcine cells. By manipulating the porcine humoral immune response, certain Salmonella strains might be able to persist better than strains that do not interfere with the immune response in pigs.

Besides direct SPI mediated effects on MHC recruitment, expression of MHC molecules may be affected by other Salmonella induced effects on macrophages, like cytotoxicity and altered macrophage activation status. Salmonella infection of porcine macrophages results in a type of cell death called pyroptosis. In contrast to apoptosis, Salmonella induced pyroptosis affects plasma membrane integrity and might thus interfere with the expression of macrophage surface molecules [14]. Furthermore, Salmonella infection of mammalian cells induces the production of reactive oxygen species (ROS) as part of the cellular immune response to eradicate intracellular pathogens and might also interfere with the expression of surface molecules $[15,16]$.

In the present study, we examined whether a Salmonella Typhimurium strain, which can persist in pigs, is able to downregulate MHC expression on porcine macrophages in a SPI-1 and/or SPI-2 dependent way, as a possible mechanism to circumvent antibody production by the pig's immune system. Furthermore, in an attempt to elucidate the importance for Salmonella to interfere with the antibody response in pigs, we verified the role of Salmonella specific antibodies in the bacterium's ability to interfere with the MHC presentation pathway and in intracellular proliferation of Salmonella in porcine macrophages. Finally, we examined whether different Salmonella strains exhibit similar effects on MHC II expression.

\section{Materials and methods}

\section{Bacterial strains and manipulations}

Salmonella Typhimurium strain 112910a was isolated from a pig stool sample and several experimental infections showed that this strain was able to persistently infect piglets $[17,18]$ without inducing significant seroconversion until at least 4 weeks post inoculation [unpublished observations]. Salmonella Typhimurium strain 112910a hilA and $s s r A / B$ deletion mutants (hereafter named $\Delta$ hil $A$ and $\triangle s s r A / B$, respectively) were constructed according to the one-step inactivation method described by Datsenko and Wanner [19] and slightly modified for use in Salmonella Typhimurium as described before [20,21]. Subsequently, the kanamycin resistance cassette was removed using the helper plasmid pCP20 [19]. The hilA gene and the $s s r A / B$ operon encode major SPI-1 and SPI-2 regulators, respectively [22,23]. Gene complementations for the deletion mutants $\triangle$ hilA and $\triangle s s r A / B$ were constructed using vector plasmid pGV1106 [24]. In short, plasmid pGV1106 was digested with EcoRI and BglII restriction enzymes (New England Biolabs, Ipswich, Massachusetts, USA), ligated with the PCR amplified linear hilA gene or $s s r A / B$ operon (primers are given in Table 1) and electroporated into electrocompetent Escherichia coli K514 and plated on Luria-Bertani agar (LB agar; Sigma-Aldrich, Chemie Gmbh, Steinheim, Germany) with $25 \mu \mathrm{g} / \mathrm{mL}$ kanamycin (Sigma-Aldrich). The resulting complementation plasmids were isolated and hilA and $s s r A / B$ inserts were sequenced to verify if the promoter sequence and the complete coding sequence were inserted. pGV1106 plasmids containing the hilA gene or $s s r A / B$ operon insert were then electroporated in the respective deletion mutants. The resulting complemented deletion mutants are further abbreviated as $\Delta h i l A^{\mathrm{c}}$ or $\Delta s s r A / B^{\mathrm{c}}$, respectively.

In addition to Salmonella Typhimurium strain 112910a, other strains used in this study were Salmonella Typhimurium pig isolates MB2150, MB2216, MB2222, MB2223, MB2233 and MB2498 and the pigeon isolate DAB69 [25], one isolate of Salmonella serovars Brandenburg, Derby and Infantis, all isolated from pigs and a chicken isolate Salmonella serovar Enteritidis 76Sa88 [26]. Finally, an Escherichia coli strain p4:o32 isolated from a bovine mastitis case was tested [27].

For flowcytometrical analysis of Salmonella infected macrophages, all Salmonella strains were transformed with the pFPV25.1 carbenicillin-resistant plasmid expressing green fluorescent protein (GFP) under the constitutive promoter of rps $M$ [28]. For inoculation of macrophages, bacteria were grown for $16 \mathrm{~h}$ at $37^{\circ} \mathrm{C}$ in $5 \mathrm{~mL} \mathrm{LB}$ broth with $25 \mu \mathrm{g} / \mathrm{mL}$ carbenicillin (Sigma-Aldrich) for selective growth of GFP-transformed bacteria.

Table 1 Primers used in this study

\begin{tabular}{ll}
\hline Name & Sequence \\
\hline HilAcomplFW & $5^{\prime}$-gggagatctgtaaaacgacggccagtcggctttaaccctgtggatt-3' \\
\hline HilAcomplRV & $5^{\prime}$-ggggaattcggataacaattcacacaggtgcatatctcctctctcagat- \\
& $3^{\prime}$ \\
\hline SsrA/BcomplFW & $5^{\prime}$-gggagatctgaatgcattagacatgcctcggtcagtcgtttagcct-3' \\
\hline SsrA/BcomplRV & $5^{\prime}$-ggggaattcacatagctatttttctgatcggggctaatgctagtcct-3' \\
\hline Primers used to create the $\triangle$ hilA and $\triangle s s r A / B$ gene complementations.
\end{tabular}




\section{Pig antisera against Salmonella Typhimurium}

Pig antisera were raised in Salmonella-negative piglets, as approved by the ethical committee of the Faculty of Veterinary Medicine, Ghent University (EC2008/124). To prepare positive serum, piglets were intramuscularly injected twice, with a 3 weeks interval, with $2 \mathrm{~mL}$ of a bacterin consisting of equal volumes of formalininactivated Salmonella Typhimurium strain 112910a suspended in phosphate buffered saline (PBS; $5 \times 10^{8}$ colony forming units (CFU) per $\mathrm{mL}$, before inactivation) and Freund's incomplete adjuvant. Negative serum was prepared in piglets injected twice with $2 \mathrm{~mL}$ of an emulsion consisting of equal volumes of PBS and Freund's incomplete adjuvant. Blood samples were collected from the jugular vein using VenoJect blood collection tubes (Terumo Europe N.V., Leuven, Belgium). The blood samples were incubated for $1 \mathrm{~h}$ at $37{ }^{\circ} \mathrm{C}$ to facilitate blood clotting and were then centrifuged for $10 \mathrm{~min}$ at $520 \times g$ and $20{ }^{\circ} \mathrm{C}$. Serum was collected and tested for the presence of Salmonella specific antibodies using a commercially available LPS-based swine Salmonella Typhimurium test kit (IDEXX Europe B.V., Hoofddorp, The Netherlands) according to the manufacturer's guidelines. Serum samples were stored at $-80^{\circ} \mathrm{C}$ until further use.

Bacteria were opsonized by adding an equal volume of pig serum to a Salmonella Typhimurium 16 h culture, containing approximately $1 \times 10^{9} \mathrm{CFU}$ per $\mathrm{mL}$, and by subsequent incubation for $20 \mathrm{~min}$ at $37^{\circ} \mathrm{C}$ on a shaker. For complement inactivation, the sera were placed at $56{ }^{\circ} \mathrm{C}$ for $10 \mathrm{~min}$ prior to opsonization.

\section{Macrophage assays}

Porcine alveolar macrophages were isolated from lungs of humanely euthanized Salmonella-free piglets as described previously [29]. Using this isolation method, the purity of the macrophage pellets varied between $90 \%$ and $97 \%$ and the viability was more than 95\% [20]. Macrophage pellets were suspended in foetal calf's serum (FCS; Gibco Life Technologies, Ghent, Belgium) with 10\% DMSO (Sigma-Aldrich) and stored in liquid nitrogen at approximately $10^{7}$ cells per $\mathrm{mL}$ until further use. Prior to seeding, macrophages were thawed at room temperature, washed in $10 \mathrm{~mL}$ Hank's buffered salt solution (HBSS; Gibco) containing 10\% FCS (and without FCS for the macrophage activation assay) and centrifuged at $520 \times g$ for $10 \mathrm{~min}$ at $4{ }^{\circ} \mathrm{C}$. The pellet was resuspended in RPMI medium composed of Roswell Park Memorial Institute medium with phenol red (RPMI; Gibco), 10\% v/v FCS, $2 \mathrm{mM}$ sodium pyruvate (Gibco), 2 $\mathrm{mM}$ L-glutamine (Gibco), $1 \mathrm{~mL}$ v/v MEM non essential amino acids $100 \times$ (Gibco) and $100 \mu \mathrm{g} / \mathrm{mL}$ penicillin and streptomycin (Gibco), unless otherwise stated. The number of macrophages per $\mathrm{mL}$ as well as their viability was determined using trypan blue exclusion and a counting chamber (Bürker, Marienfeld, Germany). All macrophage assays were conducted 3 times independently in triplicate, unless otherwise stated, with macrophages from 3 different pigs.

\section{The effect of Salmonella enterica infection on MHC expression on porcine macrophages}

Macrophages were seeded in a 29-well plate in $25 \mathrm{~cm}^{2}$ tissue culture treated flasks with filter cap (Greiner BioOne) at $5 \times 10^{6}$ cells per flask. Macrophages were allowed to adhere for $2 \mathrm{~h}$ at $37{ }^{\circ} \mathrm{C}$ and were then inoculated with Salmonella Typhimurium strain 112910a that was either not opsonized, opsonized with porcine serum containing anti-Salmonella Typhimurium antibodies or opsonized with negative pig serum, at a multiplicity of infection (MOI) of 10. Flasks were centrifuged at $520 \times g$ for $10 \mathrm{~min}$ at $37^{\circ} \mathrm{C}$ and subsequently incubated at $37^{\circ} \mathrm{C}$ for $30 \mathrm{~min}$. Macrophages were washed 3 times with HBSS containing calcium and magnesium (HBSS+; Gibco) and treated with $100 \mu \mathrm{g} / \mathrm{mL}$ gentamicin (SigmaAldrich) in RPMI for $1 \mathrm{~h}$ at $37{ }^{\circ} \mathrm{C}$ to kill all extracellular bacteria. The cells were washed again 3 times with HBSS + and fresh medium was added. This timepoint was considered as $0 \mathrm{~h}$ post inoculation. Macrophages were scraped off of the flask's bottom at 0 and $24 \mathrm{~h}$ post inoculation using rubber cell scrapers (Greiner Bio-One), washed with $5 \mathrm{~mL}$ ice-cold HBSS and resuspended in medium. These suspensions were equally distributed over 2 flowcytometry tubes (Becton-Dickinson Labware Europe, Meylan-Cedex, France). Macrophages were incubated with $10 \%$ complement inactivated Salmonella-negative goat serum and $10 \%$ complement inactivated Salmonella-negative pig serum for $15 \mathrm{~min}$ on ice to reduce background staining. After centrifugation, macrophage pellets were resuspended in a primary antibody mixture or in RPMI for the negative controls. The primary antibody mixtures were composed of RPMI, 15\% FCS and 2\% mouse anti-pig SLA class I (1:50 diluted; AbD Serotec, Kidlington, Oxford, UK) or $20 \%$ mouse anti-pig SLA class II DQ (1:5 diluted; AbD Serotec). After $50 \mathrm{~min}$ incubation on ice, cells were washed with ice-cold HBSS to remove unbound antibodies. After centrifugation, macrophage pellets were resuspended in a secondary antibody mixture or RPMI for the negative control tubes, and incubated for $50 \mathrm{~min}$ on ice and in the dark. The secondary antibody mixture contained RPMI, 15\% FCS and 2\% goat anti-mouse Alexa Fluor 633 antibody (1:50 diluted; Molecular Probes, Oregon, USA). Macrophages treated with only the primary or secondary antibody mixture served as controls. After a final washing step, the pellets were resuspended in $0.5 \mathrm{~mL}$ ice-cold HBSS for flowcytometric analysis. Flowcytometric measurements were performed using a FACScanto ${ }^{\mathrm{TM}}$ II cytometer (Becton-Dickinson, Erembodegem, Belgium). 
First, macrophages were discriminated from bacteria and debris based on forward (FSC) and side (SSC) light scatter (parent population). Subsequently, Salmonella infected macrophages were distinguished from uninfected macrophages in the parent population, based on GFP fluorescence using the FL-1 fluorescence channel, and the MHC I and II expression levels of infected and uninfected macrophages were measured using the FL-5 fluorescence channel. Data were expressed in arbitrary units and the mean FL-5 value of Salmonella infected and uninfected macrophages were calculated using the FACSDiva software (Becton-Dickinson).

Exactly the same procedure was used for macrophage infection and subsequent detection of MHC II expression levels with all other strains and mutants used in this study.

\section{Invasion capacity}

As a measure for the Salmonella invasion capacity in macrophages, the number of macrophages infected by strain 112910 that was opsonized with negative or positive pig serum, or by any other Salmonella strain at $0 \mathrm{~h}$ pi, as assessed by measurement in the FL-1 fluorescence channel, was expressed as the percentage relative to the macrophages infected by strain 112910a at the same timepoint. Salmonella Typhimurium $\Delta$ hilA, that is impaired in macrophage invasion [20], and its complement $\Delta h i l A^{\mathrm{c}}$ were used as internal controls for the use of flowcytometrical data to assess Salmonella invasion capacity.

\section{Macrophage viability assay}

We used the neutral red uptake assay to assess possible cytotoxic effects of Salmonella infection on macrophage viability. Macrophages were cultured and inoculated in a 96-well plate as described above for the flowcytometry experiments. Twenty-four hours after inoculation, $200 \mu \mathrm{L}$ of freshly prepared neutral red solution (33 $\mu \mathrm{g} / \mathrm{mL}$ neutral red (Merck N.V./S.A., Overijse, Belgium) in RPMI without phenol red), prewarmed at $37{ }^{\circ} \mathrm{C}$, was added to each well and plates were incubated for $2 \mathrm{~h}$ at $37{ }^{\circ} \mathrm{C}$. Macrophages were washed 3 times with $\mathrm{HBSS}+$ and treated with $170 \mu \mathrm{L}$ extracting solution, composed of absolute ethanol/distilled water/glacial acetic acid 50/49/1 (v/v/v), for $10 \mathrm{~min}$ at room temperature on a shaker to release the neutral red dye. Hundred microliter from each well were transferred to an IWAKI multi well plate and the absorbance was determined at $540 \mathrm{~nm}$ using a microplate ELISA reader (Multiscan MS, Thermo Labsystems, Helsinki, Finland). Macrophage cell viability at $24 \mathrm{~h}$ post inoculation (pi) was expressed as the percentage of viable macrophages compared to uninfected macrophages at this timepoint.

\section{Impact of opsonization with antibodies on intracellular proliferation of Salmonella Typhimurium in porcine macrophages}

Macrophages were seeded in a 29 -well plate at $2 \times 10^{5}$ per well and were inoculated at MOI 10 with Salmonella Typhimurium strain 112910a that was either nonopsonized, opsonized with porcine serum containing Salmonella Typhimurium specific antibodies or opsonized with negative pig serum. Macrophages were then treated with $100 \mu \mathrm{g} / \mathrm{mL}$ gentamicin as described above. After 0 or $5 \mathrm{~h}$ incubation at $37{ }^{\circ} \mathrm{C}$, macrophages were lysed using $0.2 \%$ Triton X-100 (Sigma-Aldrich) and 10-fold dilutions were plated on brilliant green agar (BGA; International Medical Products N.V./S.A., Brussels, Belgium) to enumerate viable intracellular bacteria.

\section{Macrophage activation assay}

To assess the influence of Salmonella infection on the macrophage activation status, the production of reactive oxygen species (ROS) by macrophages was measured using the lucigenin assay [30]. Macrophages were suspended in RPMI medium without phenol red and without FCS, and seeded at $2 \times 10^{5}$ cells per well in a 96-well cell culture plate (Greiner Bio-One). After $2 \mathrm{~h}$ incubation at $37{ }^{\circ} \mathrm{C}$, lucigenin (Sigma-Aldrich) solution at a final concentration of $400 \mu \mathrm{M}$ and Salmonella were added to each well at MOI 10. Positive control wells were treated with $20 \mu \mathrm{g} / \mathrm{mL}$ phorbol 12-myristate 13-acetate (PMA; Sigma-Aldrich) solution in dimethyl sulfoxide (DMSO; Sigma-Aldrich) to induce macrophage activation. Luminescence was measured every 2 min for 5 consecutive hours using a Fluoroskan Ascent Microplate Fluorometer (Thermo Fisher Scientific, Breda, The Netherlands) with $1000 \mathrm{~ms}$ integration time at $37^{\circ} \mathrm{C}$. The ROS production of infected macrophages was expressed relative to the ROS production of PMA treated macrophages (positive control).

\section{Dot blot}

Macrophages were seeded, inoculated with Salmonella Typhimurium strain 112910a at MOI 100 and incubated in $75 \mathrm{~cm}^{2}$ tissue culture treated flasks with filter cap (Greiner Bio-One) as described above for the flowcytometric experiments. At $0 \mathrm{~h}$ and $24 \mathrm{~h}$ post inoculation, macrophages were scraped off in HBSS + with a cell scraper, brought in a $15 \mathrm{~mL}$ tube and centrifuged at $520 \times \mathrm{g}$ for $10 \mathrm{~min}$ at $37{ }^{\circ} \mathrm{C}$. The cells were lysed for $90 \mathrm{~min}$ on ice in $1 \mathrm{~mL}$ of freshly prepared RIPA buffer composed of $150 \mathrm{mM} \mathrm{NaCl}$ (VWR International BVBA, Leuven, Belgium); 1.0\% Triton X-100 (Sigma-Aldrich); $0.5 \%$ sodium deoxycholate (Sigma-Aldrich); $50 \mathrm{mM}$ Tris pH 8.0 (Sigma-Aldrich); and protease inhibitor cocktail (1:10 diluted; SigmaAldrich). Additionally, all samples were sonicated for $4 \times 20$ s on ice with an Ultrasonic Processor Sonicator XL (Misonix Incorporated, Farmingdale, USA), brought to the 
same protein concentration using the Bradford-based Protein Assay (Bio-Rad Laboratories, USA), according to the manufacturer's guidelines, and stored at $-80{ }^{\circ} \mathrm{C}$ until further use.

Eight $\mu \mathrm{L}$ of each sample was spotted on a Trans-Blot nitrocellulose membrane (Bio-Rad Laboratories) and air dried for $10 \mathrm{~min}$. All subsequent incubation and washing steps were performed on a shaker at room temperature. The membrane was incubated for $30 \mathrm{~min}$ in blocking buffer composed of TBS-T buffer (20 mM Tris; $15 \mathrm{mM}$ $\mathrm{NaCl} ; 0.05 \%$ Tween-20 (Merck, Schuchardt, Germany) at $\mathrm{pH} 7.5$ ) with $5 \%$ bovine serum albumin (BSA; SigmaAldrich). The primary antibody mixture (1:100 diluted mouse anti-pig SLA class II DQ in $0.1 \%$ BSA/TBS-T buffer) was applied onto the membrane for $1 \mathrm{~h}$. The membrane was washed $3 \times 5$ min with TBS-T buffer and subsequently incubated for $1 \mathrm{~h}$ with the secondary antibody mixture (1:5000 diluted HRP-conjugated goat antimouse IgG (Jackson Immuno Research Laboratories, USA) in $0.1 \% \mathrm{BSA} / \mathrm{TBS}-\mathrm{T}$ buffer). After washing the membrane $1 \times 15 \mathrm{~min}$ and $2 \times 5 \mathrm{~min}$ in TBS-T and $1 \times 5$ min in TSB (without Tween-20), the CN/DAB substrate kit (Thermoscientific, USA) was applied onto the membrane, according to the manufacturer's guidelines. The membrane was scanned with the GS-800 densitometer (Bio-Rad Laboratories) and visually evaluated. In addition, individual spot densities were calculated and expressed as arbitrary densitometry units using the Quantity One software (Bio-Rad Laboratories).

Level of $h i l A, \operatorname{sop} B, s s r A / B$ and $s s a H$ expression in different Salmonella strains

The pCS26 plasmid was used for the construction of transcriptional fusions between the promoter regions of Salmonella Typhimurium hilA, sopB, ssr $A / B$ or $s s a H$ genes on one hand, and $\operatorname{lu} x C D A B E$ genes on the other hand, as decribed before [31,32]. Plasmids with the transcriptional fusions were isolated using the Qiagen Plasmid Midi Kit (Qiagen, Venlo, The Netherlands), electroporated in electrocompetent Salmonella bacteria and plated on LB agar with $100 \mu \mathrm{g} / \mathrm{mL}$ kanamycin (Sigma-Aldrich) for selective growth of transformants. Bacteria containing the transcriptional fusions were grown for $16 \mathrm{~h}$ in LB with $100 \mu \mathrm{g} / \mathrm{mL}$ kanamycin and 1:10000 diluted in LB. Luminescence was measured every $15 \mathrm{~min}$ for $24 \mathrm{~h}$ using a Fluoroskan Ascent Microplate Fluorometer (Thermo Fisher Scientific Inc.) with $5000 \mathrm{~ms}$ integration time at $37^{\circ} \mathrm{C}$. The extent of hilA, $\operatorname{sop} B, s s r A / B$ and $s s a H$ gene expression is presented as the integral of relative luminescence units (RLU) over a $24 \mathrm{~h}$ measurement period.

\section{Statistical analysis}

The capacity to downregulate $\mathrm{MHC}$ expression was determined by calculating the average mean FL-5 ratio between Salmonella infected and uninfected macrophages at $0 \mathrm{~h}$ and $24 \mathrm{~h}$ post inoculation (pi) of 3 independent experiments. Differences in MHC expression level between macrophages infected with strain 112910a, either opsonized or not opsonized, and its isogenic mutants at $0 \mathrm{~h}$ and $24 \mathrm{~h}$ pi were evaluated using a oneway ANOVA on the calculated mean ratios, assuming normal distribution and equal variances. The MHC II expression level of macrophages inoculated with different Salmonella strains was evaluated using a paired Student's $t$-test on the calculated mean ratios at $0 \mathrm{~h}$ and 24 $\mathrm{h}$ pi. Intracellular proliferation of Salmonella strain 112910a in macrophages was evaluated using an independent samples Student's $t$-test with log CFU per $\mathrm{mL}$ as dependent and group as fixed factor.

The invasion capacity of strain 112910a, either opsonized or not with positive or negative pig serum, and its isogenic mutants $\Delta$ hilA and $\Delta$ hil $A^{\mathrm{c}}$ was compared using a one-way ANOVA, assuming normal distributions and equal variances. ROS production by macrophages infected with Salmonella strain 112910a that was either not opsonized, or opsonized with negative or positive pig serum prior to inoculation of macrophages, was analyzed using an unpaired Student's $t$-test with equal variances not assumed. Differences in Salmonella invasiveness and in the effects of Salmonella on macrophage viability and ROS production for the different Salmonella strains were evaluated using a one-way ANOVA, assuming normal distributions and equal variances. Correlations between MHC expression on one hand, and Salmonella invasiveness, macrophage viability, ROS production or hilA, sopB, ssr $A / B$ and $s s a H$ gene expression on the other hand, were evaluated using the Pearson's correlation test on the respective datasets. Spot densities from the dot blot assay were evaluated using unpaired two-tailed Student's $t$-tests and a one-way ANOVA, assuming normal distributions and equal variances.

A $p$-value $\leq 0.05$ was considered statistically significant and a value of $0.05<p \leq 0.10$ was considered borderline significant. All statistical analyses were performed using the SPSS 19.0 software (IBM Corporation, New York, USA).

\section{Results}

Salmonella Typhimurium strain 112910 a reduces MHC II but not MHC I expression on porcine macrophages in a SPI-1 and SPI-2 dependent way

To examine the effect of a Salmonella Typhimurium strain 112910a infection on MHC I and II expression, the expression of MHC molecules on the surface of 112910a infected macrophages and uninfected macrophages $\left(\mathrm{PAM}^{112910 \mathrm{a}}\right.$ and PAM ${ }^{\mathrm{uninf}}$, respectively) was measured immediately $(0 \mathrm{~h})$ and $24 \mathrm{~h}$ post inoculation (pi). Ratios were calculated as the 
average mean ratio of 3 independent experiments. At $0 \mathrm{~h}, \mathrm{PAM}^{112910 \mathrm{a}} / \mathrm{PAM}^{\text {uninf }}$ was $1.054( \pm 0.011)$ and 0.990 ( \pm 0.083) for MHC I and MHC II, respectively, corresponding to equal MHC expression levels on uninfected macrophages and macrophages infected with strain 112910a. At $24 \mathrm{~h}$ pi, PAM ${ }^{112910 a} /$ PAM $^{\text {uninf }}$ for MHC I did not significantly differ from the average ratio at $0 \mathrm{~h}$ pi $(p>0.05)$, suggesting that the MHC I expression level of PAM ${ }^{112910 a}$ remained unaffected. In contrast to this, PAM ${ }^{112910 a} / \mathrm{PAM}^{\text {uninf }}$ for MHC II expression at $24 \mathrm{~h}$ pi was significantly lower than at $0 \mathrm{~h}(p \leq 0.05)$, corresponding to a decreased MHC II expression level on PAM $^{112910 a}$. These results are summarized in Figure 1A and show that Salmonella Typhimurium strain 112910a specifically downregulates MHC II expression on porcine macrophages.

To determine the possible role of Salmonella Pathogenicity Island 1 and/or 2 (SPI-1 and SPI-2, respectively) in Salmonella induced downregulation of MHC II expression on macrophages, the expression level between uninfected macrophages (PAM ${ }^{\text {uninf }}$ ) and macrophages infected with either strain 112910a $\left(\mathrm{PAM}^{112910 \mathrm{a}}\right)$, its isogenic deletion mutants $\Delta$ hilA $\left(\mathrm{PAM}^{\Delta \text { hilA }}\right), \Delta s s r A / B\left(\mathrm{PAM}^{\Delta s s r A / B}\right)$ or their respective complements $\Delta h i l A^{\mathrm{c}}\left(\mathrm{PAM}^{\Delta \text { hilAc }}\right)$ and $\triangle s s r A / B^{\mathrm{C}}$ $\left(\mathrm{PAM}^{\triangle s s r A / B c}\right)$ was compared. At $0 \mathrm{~h}$, mean $\mathrm{MHC}$ II expression level ratios between Salmonella infected and uninfected macrophages were approximately 1 for macrophages inoculated with strain 112910a or its isogenic mutants and did not significantly differ from each other $(p>0.05)$. At $24 \mathrm{~h}$ pi, $\mathrm{PAM}^{\Delta h i l A} / \mathrm{PAM}^{\text {uninf }}$ and $\mathrm{PAM}^{\Delta s s r A / B} / \mathrm{PAM}^{\text {uninf }}$ were significantly higher than $\mathrm{PAM}^{112910 \mathrm{a}} / \mathrm{PAM}^{\text {uninf }}$ at the same timepoint $(p<0.05)$, suggesting at least partial inhibition of $\mathrm{MHC}$ II downregulation when hilA or $s s r A / B$ was deleted. Furthermore, complementation of the respective deletion mutants resulted in $\mathrm{PAM}^{\Delta h i l A \mathrm{c}} / \mathrm{PAM}^{\text {uninf }}$ and $\mathrm{PAM}^{\Delta s s r A / B \mathrm{c}} / \mathrm{PAM}^{\text {uninf }} 24 \mathrm{~h}$ pi that did not significantly differ from PAM $^{112910 a} /$ PAM $^{\text {uninf }}$ at the same timepoint $(p \geq 0.05)$, indicating functional restoration of the wild type phenotype. The fact that $\mathrm{PAM}^{\Delta s s r A / B} / \mathrm{PAM}^{\text {uninf }} 24 \mathrm{~h}$ pi was still significantly lower than the same ratio at $0 \mathrm{~h} \mathrm{pi}$, while this was not the case for $\mathrm{PAM}^{\Delta \text { hilA }} / \mathrm{PAM}^{\text {uninf }}$, suggests a more important role for SPI-1 than for SPI-2 in Salmonella induced downregulation of MHC II expression on macrophages. These results are summarized in Figure 1A.

\section{Opsonization of Salmonella Typhimurium strain 112910a with Salmonella specific antibodies inhibits downregulation of MHC II expression on, limits intracellular proliferation in and enhances ROS production by macrophages}

Because Salmonella Typhimurium strain 112910a was able to downregulate MHC II expression on porcine macrophages, and might thus interfere with the MHC II dependent pig's antibody response towards Salmonella infection, we wanted to examine if opsonization of Salmonella with Salmonella specific antibodies was detrimental to the bacterium's MHC II downregulating and intracellular proliferation capacity in porcine macrophages.

First, we examined the effect of opsonization with serum antibodies on Salmonella induced downregulation of MHC II expression on porcine macrophages. Macrophages were inoculated with bacteria opsonized either with pig serum containing anti-Salmonella Typhimurium antibodies $\left(\mathrm{PAM}^{112910 \mathrm{aPOS})}\right.$ or with negative pig serum $\left(\mathrm{PAM}^{112910 \mathrm{NEG}}\right)$. At $0 \mathrm{~h}$, average mean PAM $^{112910 \mathrm{a}}$ / PAM $^{\text {uninf, }}$ PAM $^{112910 a N E G} /$ PAM $^{\text {uninf }}$ and PAM ${ }^{112910 a P O S} /$ PAM $^{\text {uninf }}$ were $0.990 \pm 0.043 ; 1.172 \pm 0.088$ and $1.161 \pm 0.101$ and did not significantly differ from each other $(p>0.05$; Figure $1 \mathrm{~A})$. After $24 \mathrm{~h}$ incubation, PAM $^{112910 a N E G} /$ PAM $^{\text {uninf }}$ was significantly lower than $\mathrm{PAM}^{112910 \mathrm{aNEG}} / \mathrm{PAM}^{\text {uninf }}$ at $0 \mathrm{~h}$ pi on one hand $(p \leq 0.05)$, and than $\mathrm{PAM}^{112910 \mathrm{aPOS}} / \mathrm{PAM}^{\text {uninf }}$ at $24 \mathrm{~h}$ pi on the other hand $(p \leq 0.05)$, while PAM $^{112910 a P O S} / \mathrm{PAM}^{\text {uninf }}$ at $24 \mathrm{~h}$ did not significantly differ from the ratio at $0 \mathrm{~h}$ pi $(p>0.05)$. This shows that opsonization of strain 112910a with Salmonella specific serum antibodies suppressed the bacterium's ability to downregulate MHC II expression on macrophages (Figure 1A).

When strain 112910 was opsonized with either positive or negative pig serum prior to infection of macrophages, based on flowcytometrical data, significantly more macrophages were infected compared to macrophages inoculated with non opsonized bacteria ( $p \leq 0.05$; Figure $1 \mathrm{~B})$. As an internal control for proper use of flowcytometry to assess the Salmonella invasion capacity, the invasion capacity of strain 112910a isogenic mutants $\Delta$ hilA and $\Delta$ hilA ${ }^{\mathrm{c}}$ was determined. We found that $\triangle$ hilA was significantly impaired in macrophage invasion compared to the background strain and to its complement $\Delta$ hilA ${ }^{\mathrm{c}}(p \leq 0.05$; Figure 1B). Using a gentamicin protection assay, it was found that bacteria that were not opsonized or opsonized with negative pig serum were able to significantly proliferate intracellularly $5 \mathrm{~h}$ post inoculation of macrophages $(p \leq 0.05$; Figure 1C). Salmonellae that were opsonized with pig serum containing Salmonella specific antibodies, prior to inoculation of macrophages, did not significantly proliferate $(p>0.05$; Figure $1 C)$. Furthermore, macrophages infected with strain 112910a that was opsonized with positive pig serum showed a tendency towards the production of higher amounts of reactive oxygen species (ROS) than macrophages infected with strain 112910a that was not opsonized or opsonized with negative pig serum prior to inoculation of macrophages (Figure 1D). These differences were only statistically significant between macrophages infected with Salmonella opsonized with positive pig serum 

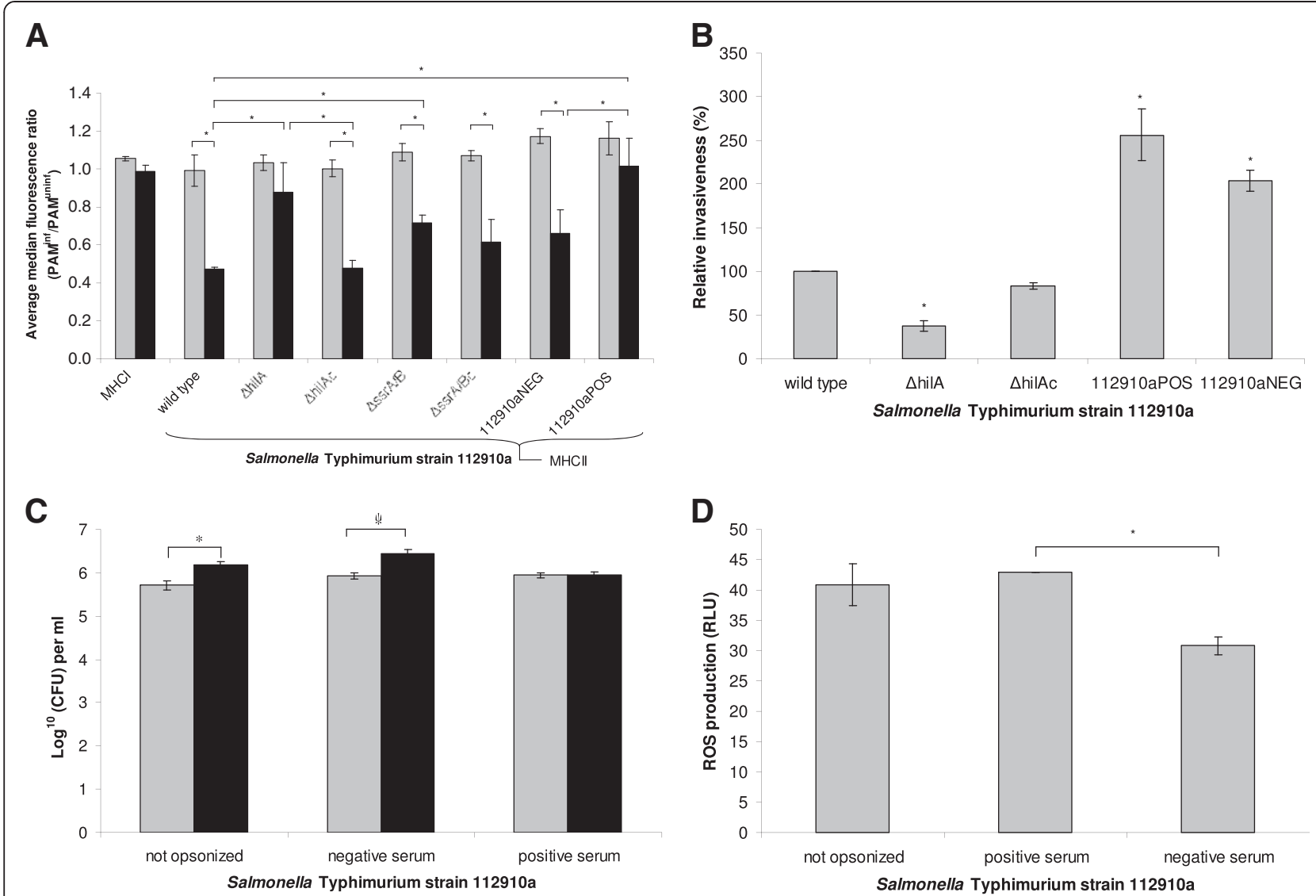

Figure 1 The capacity of Salmonella enterica to downregulate MHC expression on the surface of porcine macrophages, Salmonella invasion capacity in macrophages and the effect of opsonization of Salmonella with negative and positive pig serum on intracellular proliferation and on reactive oxygen species (ROS) production. A. The average mean PAM ${ }^{\text {inf }} /$ PAM $^{\text {uninf }}$ ratios $( \pm$ standard deviation) measured in the FL-5 channel, $0 \mathrm{~h}$ (grey bars) and $24 \mathrm{~h}$ (black bars) post inoculation (pi) with Salmonella Typhimurium strain 112910a or its isogenic deletion mutants $\triangle$ hilA and $\triangle s s r A B$, and their respective complements $\triangle h i l A^{c}$ and $\triangle s s r A / B^{c}$. The values were calculated from the ratios obtained from 3 independent experiments and an asterisk refers to a significantly different average mean fluorescence ratio $(p \leq 0.05)$. PAM ${ }^{\text {inf }}$ and PAM ${ }^{\text {uninf: }}$ infected and uninfected porcine alveolar macrophages, respectively. MHC I and MHC II: expression of MHC I or MHC II molecules, respectively, in macrophages inoculated with strain 112910a; 112910aNEG: Salmonella Typhimurium strain 112910 opsonized with negative pig serum; 112910aPOS: Salmonella Typhimurium strain 112910 opsonized with pig serum containing Salmonella Typhimurium specific antibodies. B. Salmonella Typhimurium strain 112910a invasion capacity in porcine macrophages after opsonization with negative and positive pig serum. The relative invasiveness of Salmonella Typhimurium hilA deletion mutant $(\Delta h i / A)$ and its complement $\left(\Delta h i / A^{\top}\right)$ was used as an internal control. Salmonella invasiveness was expressed as the percentage relative to the invasion capacity of strain 112910a \pm standard deviations. Each bar represents the average of three independent experiments. An asterisk (*) indicates a significantly different invasion capacity compared to strain 112910a ( $p \leq 0.05)$. C. The average ${ }^{10} \mathrm{log}$ CFU of Salmonella Typhimurium strain 112910 a that was either not opsonized, opsonized with negative pig serum or opsonized with serum containing Salmonella specific antibodies per $\mathrm{mL}$, recovered from macrophages immediately (grey bars) or 5 h (black bars) post inoculation (pi). Bars with an asterisk represent significant bacterial proliferation at $5 \mathrm{~h}$ post inoculation $(p \leq 0.05)$. D. ROS production of macrophages inoculated with Salmonella Typhimurium strain 112910a that was not opsonized or opsonized with negative or positive pig serum. The ROS production of infected macrophages was expressed relative to the ROS production of phorbol 12-myristate 13-acetate (PMA) treated macrophages (positive control). Each bar represents the average of two independent experiments conducted in triplicate. An asterisk (*) indicates a statistically significant difference in ROS production $(p \leq 0.05)$.

on one hand, and with Salmonella opsonized with negative serum on the other hand $(p \leq 0.05)$.

\section{Reduction of MHC II expression is Salmonella specific and Salmonella strain dependent}

While we found that Salmonella Typhimurium strain 112910a was able to downregulate MHC II expression on porcine macrophages, an Escherichia coli strain was not (Figure 2A). Because a typical characteristic of Salmonella pathogenesis is that it is strongly dependent on host species, serovar and even strain, we verified whether the capacity of Salmonella to downregulate MHC II expression on macrophages also differed among Salmonella strains. Among the 7 different Salmonella Typhimurium pig stool isolates tested, strain MB2216 did not induce MHC II 
downregulation on macrophages at $24 \mathrm{~h}$ pi, while the other strains exhibited downregulation of MHC II expression similar to strain 112910a (Figure 2A). Furthermore, the pigeon isolate Salmonella Typhimurium DAB69, the Salmonella Derby and Salmonella Infantis strains showed no MHC II downregulation on macrophages at $24 \mathrm{~h} \mathrm{pi}$, in contrast to the serovar Brandenburg and Enteritidis strains. We can conclude that the capacity of Salmonella to downregulate MHC II expression on macrophages is Salmonella specific and strain dependent (Figure 2A).
Strain dependent downregulation of MHC II expression on macrophages does not correlate with differences in Salmonella invasion capacity or Salmonella induced cytotoxicity and reactive oxygen species (ROS) production We verified whether the observed strain dependent capacity to downregulate MHC II expression on porcine macrophages correlated with Salmonella invasion capacity or altered macrophage viability or activation status.

First, we compared the invasion capacity of all tested Salmonella strains. Salmonella Typhimurium strain MB2498 was significantly less able to infect macrophages

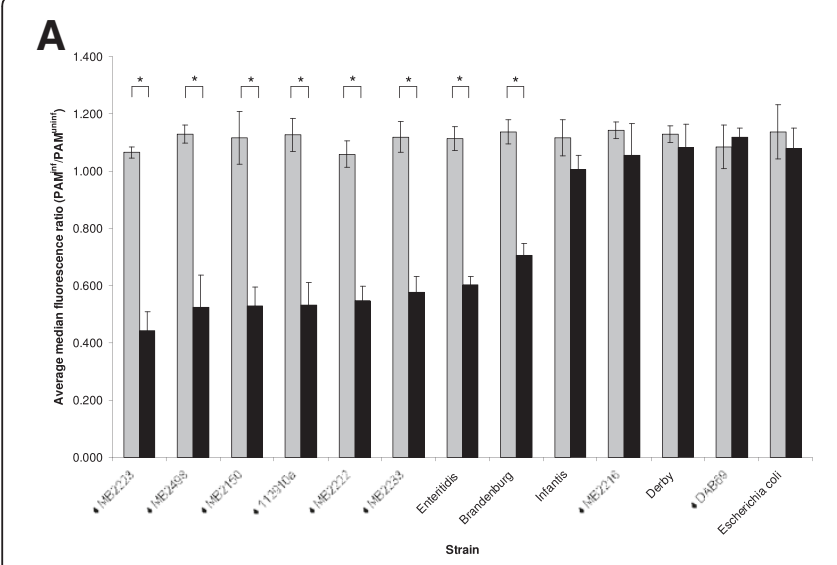

\section{B}

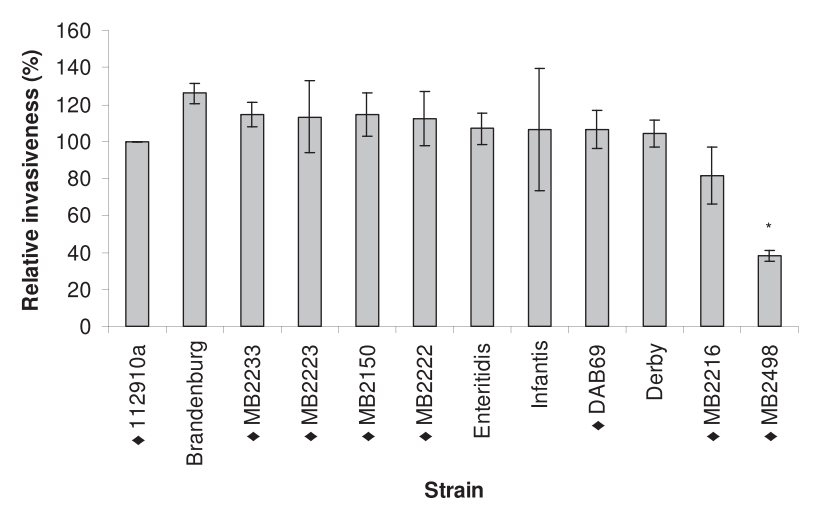

C

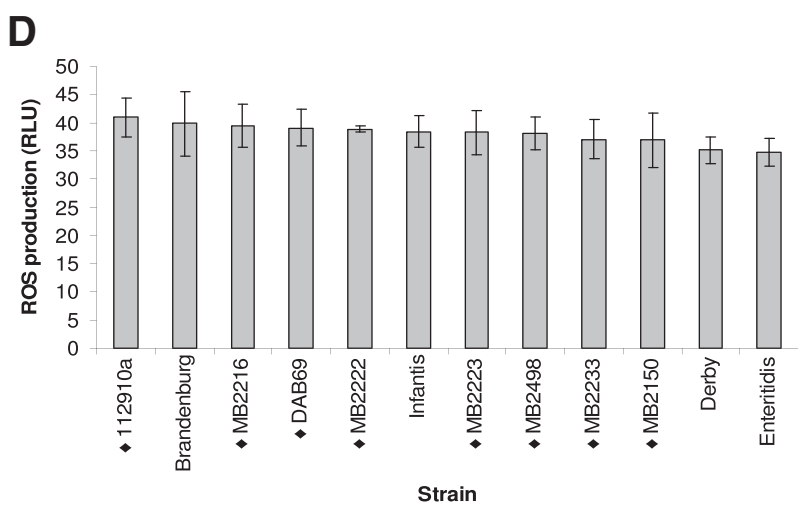

Figure 2 The capacity of different Salmonella strains to downregulate MHC expression on the surface of porcine macrophages, the Salmonella invasion capacity in macrophages, and the effect of different Salmonella strains on macrophage viability and reactive oxygen species (ROS) production. A. The average mean PAM ${ }^{\text {inf }} / \mathrm{PAM}^{\text {uninf }}$ ratios ( \pm standard deviation) measured in the FL-5 channel, $0 \mathrm{~h}$ (grey bars) and $24 \mathrm{~h}$ (black bars) post inoculation (pi) with different Salmonella strains or an Escherichia coli strain. The values were calculated from the ratios obtained from 3 independent experiments and an asterisk refers to a significantly different average mean fluorescence ratio $(p \leq 0.05)$. Salmonella Typhimurium strains are indicated with PAM $^{\text {inf }}$ and PAM ${ }^{\text {uninf }}$ : infected and uninfected porcine alveolar macrophages, respectively. B. The invasion capacity in porcine macrophages of different Salmonella strains. Salmonella Typhimurium strains are indicated with . Salmonella invasiveness was expressed as the percentage relative to the invasion capacity of strain 112910a \pm standard deviations. Each bar represents the average of three independent experiments. An asterisk $\left(^{*}\right)$ indicates a statistically significant difference in invasion capacity $(p \leq 0.05)$. $\mathbf{C}$. Macrophage viability is expressed as the average percentage of viable cells at $24 \mathrm{~h}$ post inoculation \pm standard deviation relative to viable uninfected macrophages (negative control). Each bar represents the average of three independent experiments conducted in triplicate. Salmonella Typhimurium strains are indicated with $\bullet$. An asterisk $\left(^{*}\right)$ indicates a statistically significant difference in macrophage viability $(p \leq 0.05)$. D. ROS production of macrophages inoculated with different Salmonella strains. The ROS production of infected macrophages was expressed relative to the ROS production of phorbol 12-myristate 13-acetate (PMA) treated macrophages (positive control). Each bar represents the average of two independent experiments conducted in triplicate. Salmonella Typhimurium strains are indicated with $\bullet$. 
compared to the other Salmonella strains ( $p \leq 0.05$; Figure 2B), but was able to downregulate MHC II expression comparably to, or even better than strains that showed higher infection rates (Figure 2A). We did not find a significant correlation between invasion capacity and the extent of downregulation of MHC II expression ( $r=0.001$; Figure 3A). Furthermore, we found that viability of macrophages inoculated with the tested strains differed, and that viability of DAB69 inoculated macrophages was dramatically decreased $24 \mathrm{~h}$ post inoculation (Figure $2 \mathrm{C}$ ). However, no significant correlation was found between MHC II expression level and cell viability at $24 \mathrm{~h} \quad(r=0.021$; Figure 3B). Finally, infection of macrophages with the different Salmonella strains did not significantly affect ROS production ( $p>0.05$; Figure 2D) and no significant correlation was detected between MHC II downregulation capacity and ROS production ( $r=-0.072$; Figure $3 C)$.

\section{Differential expression of SPI-1 and SPI-2 genes does not correlate with strain dependent downregulation of MHC II expression}

We showed that Salmonella Typhimurium strain 112910a induced downregulation of MHC II expression was at least partially dependent on SPI-1 and SPI-2 gene expression. Therefore we wanted to examine if the strain dependent differences in the capacity to downregulate MHC II expression on macrophages correlated with an altered expression of SPI-1 and/or SPI-2 genes. We found that various Salmonella strains expressed SPI-1 genes hilA and $\operatorname{sop} B$ to a different extent. Expression of sopB could not be detected in the Salmonella Typhimurium MB2498 and Salmonella Derby strains. No significant correlation was found between the expression levels of both genes in the different Salmonella strains [unpublished observations]. Expression of SPI-2 genes $s s r A / B$ and $s s a H$ also differed between Salmonella strains, but in contrast to expression of both SPI-1 genes, a statistically significant positive correlation was found between $s s r A / B$ and $s s a H$ expression in the strains $(p<0.05$ with $r=0.89$ ) [unpublished observations]. However, no significant correlation was found between hilA, sop $B, \operatorname{ssr} A / B$ or $s s a H$ gene expression and the capacity to downregulate MHC II expression for the tested Salmonella strains (Figure 4A-D).

\section{Dot blot}

Based on visual analysis of the dot blot, the total amount of MHC II is less $24 \mathrm{~h}$ post inoculation in both uninfected and infected macrophages compared to $0 \mathrm{~h} \mathrm{pi}$, with less MHC II molecules in Salmonella infected macrophages $24 \mathrm{~h}$ pi compared to uninfected macrophages $24 \mathrm{~h}$ pi (Figure 5). In addition, spot densities were calculated using the Quantity One software, however, no statistically significant differences
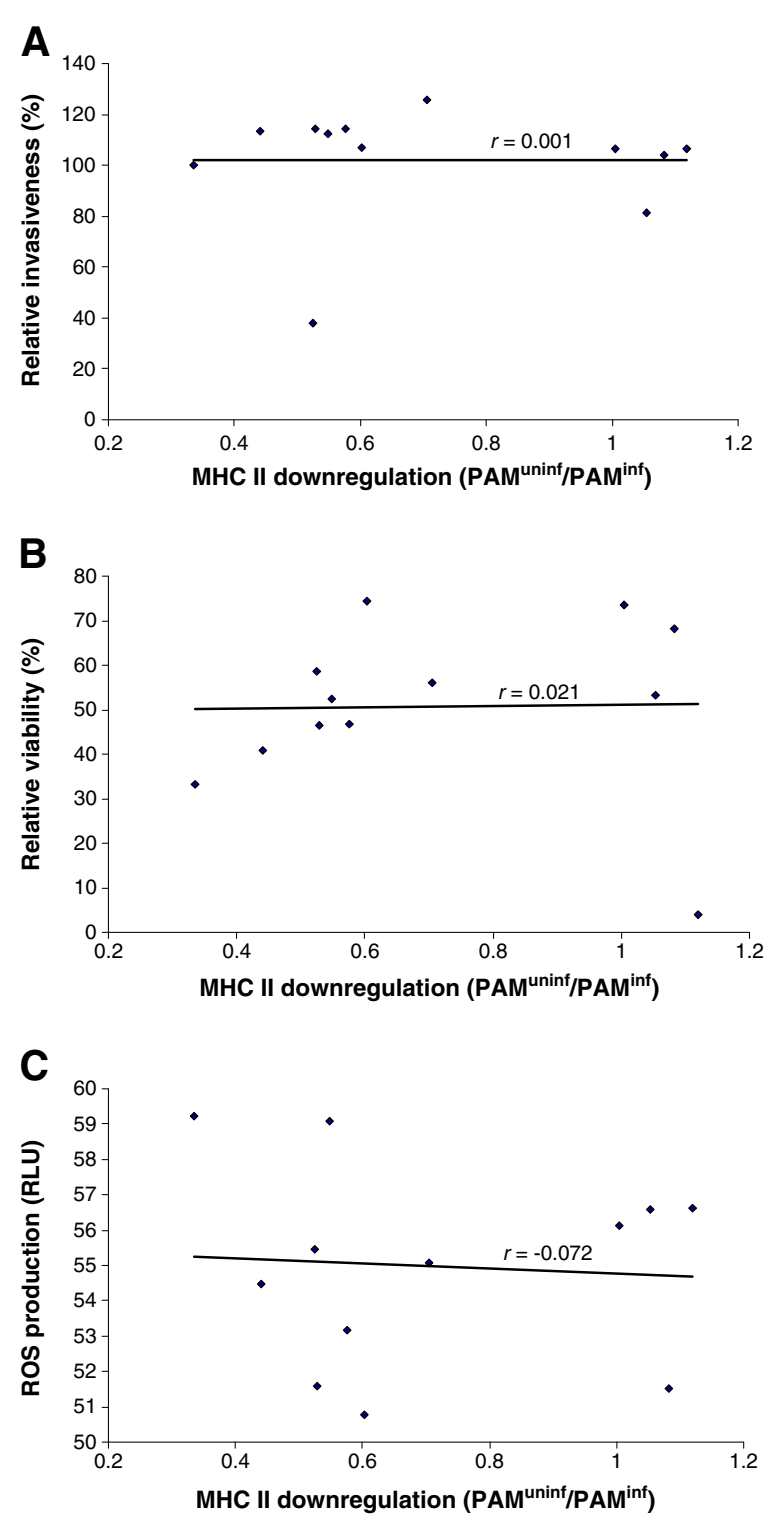

Figure 3 Correlation between MHC II downregulation and invasion capacity, cytotoxicity or ROS production. Correlation between Salmonella induced MHC II downregulation (X-axis) and (A) Salmonella invasion capacity, (B) macrophage viability or (C) ROS production (on the respective $\mathrm{Y}$-axes) with $r=$ Pearson correlation coefficient. MHC II downregulation capacity is presented as the average mean $\mathrm{FL}-5$ signal ratios between infected and uninfected porcine alveolar macrophages (PAM ${ }^{\text {inf }}$ and PAM ${ }^{\text {uninf }}$, respectively). Salmonella invasion capacity is expressed as the number of macrophages infected by a particular Salmonella strain relative to the macrophages infected by strain 112910a. Viability is expressed as the average percentage of viable cells at $24 \mathrm{~h}$ post inoculation relative to viable uninfected macrophages (negative control). ROS production of infected macrophages was expressed relative to the ROS production of phorbol 12-myristate 13-acetate (PMA) treated macrophages (positive control). ROS = reactive oxygen species; PAM = porcine alveolar macrophages. 
between the groups were detected [unpublished observations]. We therefore conclude that the overall amount of MHC II molecules is not significantly decreased $24 \mathrm{~h}$ post inoculation of macrophages.

\section{Discussion}

At present, preharvest Salmonella monitoring programs are primarily based on serological analysis, an inexpensive method that allows rapid screening of high numbers of pig herds [6]. The onset of seroconversion after Salmonella infection in pigs is difficult to predict and can range from 6 days up to 25 weeks after oral inoculation, depending on, among others, the inoculation strain and inoculation dose used and piglet age $[7,9,33,34]$. Yet, no data are available about the underlying mechanisms that account for these differences.
Seroconversion is initiated when antigen-presenting cells like macrophages and dendritic cells present pathogen-derived peptide antigens to T cells in 2 different ways. In the endogenous pathway, polypeptides that access the host cell's cytosol are degraded by the proteasome and are presented at the surface of antigen presenting cells through MHC I molecules. Salmonella, however, enters the host cell through the endocytic route, causing its peptides to be presented via MHC II molecules after lysosomal degradation [35,36]. Antigens bound to MHC II are presented to naïve CD4+ helper T cells that will develop into effector $\mathrm{T}$ cells. The latter than differentiate into two major subtypes of cells known as type 1 and type 2 helper $T$ cells $\left(T_{h} 1\right.$ and $T_{h} 2$ cells, respectively), depending on, among others, the chemo- and cytokine environment. $\mathrm{T}_{\mathrm{h}} 1$ cells predominantly activate macrophages while $T_{h} 2$ cells will induce
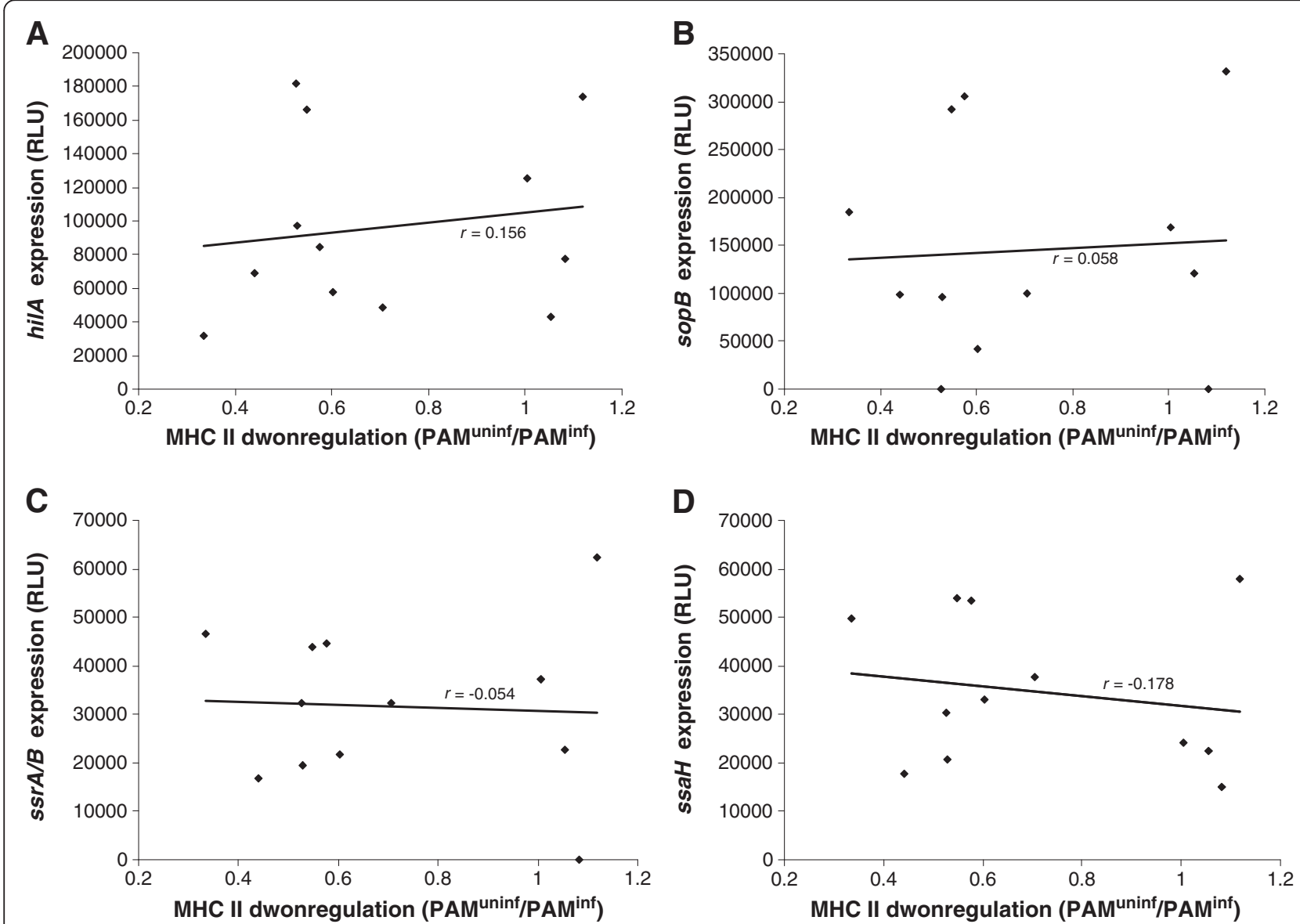

Figure 4 Correlation between MHC II downregulation and SPI-1 or SPI-2 gene expression. Correlation between MHC II downregulation capacity (X-axis) and expression of Salmonella Typhimurium SPI-1 genes hilA (A) and sopB (B) and SPI-2 genes ssrAvB (C) and ssaH (D) (on the respective $Y$-axes) by different Salmonella strains, with $r=$ Pearson correlation coefficient. Gene expression was measured as the luminescence of the respective Salmonella strain transformed with a plasmid in which the hilA, sopB, ssrA/B or ssaH promoter was cloned upstream of the reporter genes luxCDABE. Luminescence (and expression of the virulence genes) was measured in real time with a Fluoroskan luminometer during $24 \mathrm{~h}$ incubation of these strains at $37{ }^{\circ} \mathrm{C}$ in LB medium. MHC II downregulation capacity is presented as the average mean FL-5 signal ratios between infected and uninfected porcine alveolar macrophages (PAM ${ }^{\text {inf }}$ and PAM ${ }^{\text {uninf }}$, respectively). Gene expression is presented as the average relative luminescence units (RLU) of three independent measurements conducted in triplicate \pm standard deviation. 


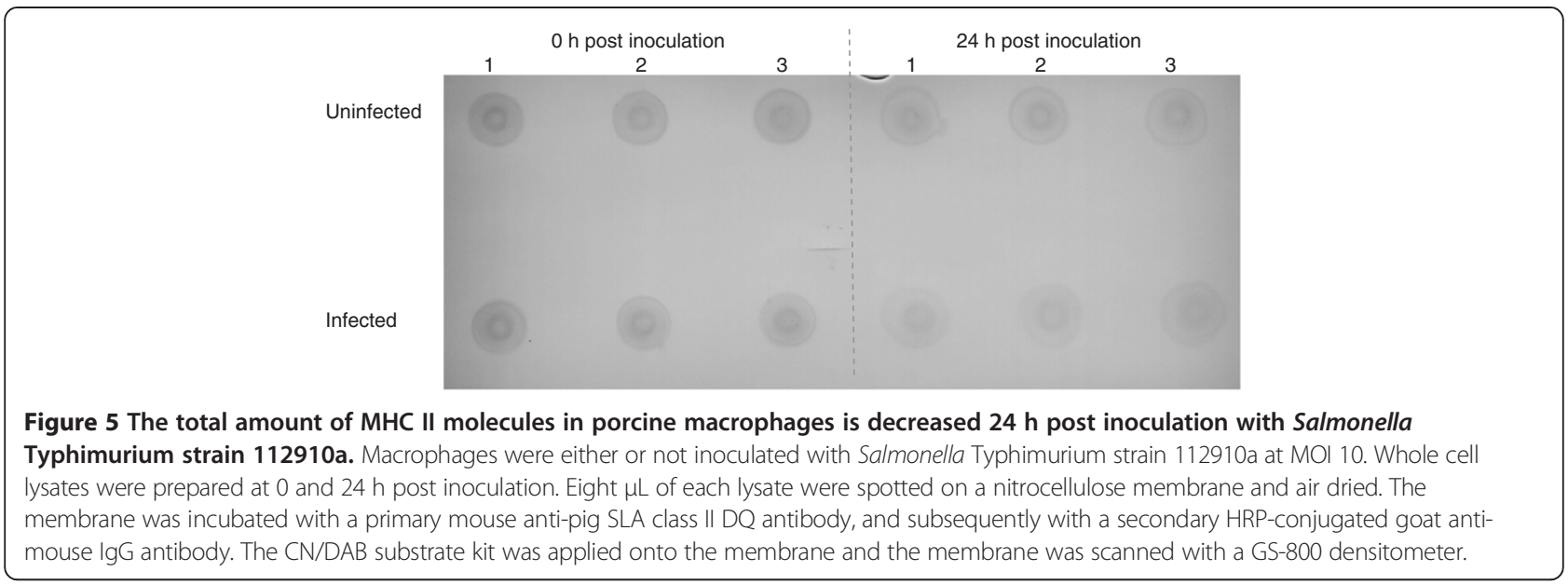

maturation of $\mathrm{B}$ cells to antibody producing plasma cells. Because the MHC II antigen presenting pathway is able to mount both a cellular and/or humoral immune response, bacteria that interfere with the MHC II expression might radically influence the host's immune response towards infection. Generally, the expression of MHC II molecules on the surface of macrophages is upregulated following ingestion of microorganisms and recognition of their foreign molecular pattern [37]. We found that Salmonella Typhimurium strain 112910a specifically downregulated MHC II expression on the surface of macrophages and that the MHC I level of macrophages remained unaffected $24 \mathrm{~h}$ post inoculation (pi). These results suggest that Salmonella specifically interferes with the MHC II presentation pathway in porcine macrophages, leaving the MHC I pathway undisturbed. Furthermore, downregulation of MHC II expression on porcine macrophages turned out to be Salmonella specific, since we found that an Escherichia coli strain, another closely to Salmonella related member of the Enterobacteriaceae family, was unable to induce MHC II downregulation. Inoculation of bovine macrophages with Salmonella Typhimurium did not cause downregulation of MHC II expression [38]. Although porcine alveolar macrophages represent a quite specific model which might explain their differential behaviour compared to macrophages or other cell types from other host species, our findings might provide further evidence for host-specific Salmonella behaviour.

Salmonella Pathogenicity Islands (SPIs') are clusters of genes encoding virulence factors that play an important role at different stages of the pathogenesis of Salmonella infections in pigs [5]. We examined whether SPI-1 and/or SPI-2 were involved in the observed Salmonella induced downregulation of MHC II expression on macrophages. Salmonella Typhimurium SPI-1 plays a crucial role in the colonization and invasion of the porcine gut [39], while SPI-2 is predominantly involved in replication and survival of Salmonella Typhimurium in porcine macrophages [20]. HilA and SsrA/B are major regulators of SPI-1 and SPI-2, respectively, and both regulators induce transcriptional activation of downstream genes in response to a variety of stimuli $[23,40]$. We found that Salmonella Typhimurium induced downregulation of MHC II expression was at least partly dependent on SPI-1 and SPI-2. Since recent evidence shows that SPI-1 is also involved in intracellular behaviour of Salmonella in macrophages, besides its main role in cell invasion [36], the fact that MHC II downregulation is inhibited when SPI-1 is abolished is not a complete surprise. Both SPI-1 and SPI-2 encode a type 3 secretion system, T3SS-1 and T3SS-2 respectively, a needle-like structure that is used to inject so called 'effector proteins' into the host cell's cytosol, for uptake of the bacterium or to adapt the intracellular environment in function of Salmonella survival. Mitchell and colleagues already showed that SPI-2 effector SifA plays a role in downregulation of MHC II expression on human Mel JuSo cells, possibly by recruiting vesicles that transport MHC II molecules to the cell membrane, to maintain the integrity of the Salmonella containing vacuole (SCV) [12]. In support of the hypothesis of redistribution of MHC II molecules from the cell surface to the SCV, our data from the dot blot assay suggest no change in the total amount of MHC II molecules in uninfected and Salmonella infected macrophages $24 \mathrm{~h}$ post inoculation. It is likely that SPI-1 and SPI-2 secreted effector proteins cause the Salmonella induced downregulation of MHC II expression on porcine macrophages. Altogether, we showed an explicit role for SPI-1 and a more discreet role for SPI-2 in downregulation of MHC II expression on porcine macrophages. However, because MHC II expression levels in $\triangle$ hilA and $\triangle s s r A / B$ infected macrophages were not completely restored, other factors than SPI-1 and SPI-2 might be involved as well.

It has commonly been assumed that resistance to facultatively intracellular bacteria like Salmonella 
Typhimurium predominantly requires a cellular immune response. However, there appear to be multiple mechanisms by which antibodies can influence the course of infection with such pathogens [41]. We found that, when Salmonella Typhimurium strain 112910a was opsonized with Salmonella specific antibodies prior to inoculation of macrophages, the bacterium lost its capacity to interfere with MHC II expression and was less able to proliferate in porcine macrophages. A proposed mechanism by which antibodies might interfere with Salmonella virulence is by sterically hindering the proper insertion of T3SS-1 and/or T3SS-2, since both secretion systems are required for successful intracellular proliferation of Salmonella [36].

Salmonella can actively invade macrophages using T3SS-1 or can be taken up passively through Fc-receptor mediated phagocytosis [42]. Besides an effect through sterical hindrance of T3SS, it is thus possible that opsonization of Salmonella with serum antibodies favoured phagocytosis over Salmonella controlled invasion. It was found that when Salmonella was opsonized prior to inoculation of macrophages, approximately 2 to 2.5 times more bacteria were internalized than in macrophages that were inoculated with non opsonized Salmonella. Salmonellae internalized into macrophages reside within Salmonella containing vacuoles (SCV) and the environment in these SCV after FC-receptor mediated phagocytosis is different from that after T3SS-1 dependent invasion [42]. These different environmental changes might subsequently result in differences in the expression of hilA and other Salmonella genes, and in this way alter the intracellular behaviour of the microorganism $[32,43,44]$. Since we showed that downregulation of MHC II expression is SPI-1 and SPI-2 dependent, differential gene expression caused by the used internalization mechanism might affect the extent of Salmonella interference with the MHC II expression on macrophages. The mechanism of Salmonella internalization might furthermore affect the macrophage activation level. Indeed, macrophages that phagocytosed Salmonella that was opsonized with Salmonella specific antibodies produced more ROS than macrophages infected with bacteria that were not opsonized, or opsonized with negative pig serum, indicating increased macrophage activation [45]. Furthermore, enhanced ROS production can result in growth inhibition of intracellular bacteria and even destruction of these bacteria [20], which might explain why Salmonella was less able to proliferate intracellularly after opsonization with Salmonella specific antibodies. Inhibition of downregulation of MHC II expression when Salmonella was opsonized with antibodies prior to inoculation of macrophages might, in addition to sterically hindering the proper insertion of T3SS-1 and/or T3SS-2, thus be the result of enhanced phagocytosis and/or ROS production and subsequent changes in Salmonella virulence gene expression. The findings that opsonization of Salmonella with specific antibodies prior to inoculation of porcine macrophages limits intracellular proliferation and inhibits downregulation of MHC II expression emphasize the importance for Salmonella to circumvent antibody production for successful persistence in the pig host.

Since strain and host specific behaviour is a key characteristic of Salmonella pathogenesis [46,47], we determined if other Salmonella isolates exhibited the same phenotype as strain 112910a. We found that the extent of MHC II downregulation differed considerably among various Salmonella strains. Salmonella Typhimurium strain MB2216, a pig isolate, and strain DAB69, a pigeon isolate, and serovar Infantis and Derby strains, both pig isolates, exhibited no downregulation of MHC II expression in the current setup.

Subsequently, it was determined if the strain specific differences in MHC II downregulation capacity were inherent to macrophage infection by that particular strain, or correlated with Salmonella invasion capacity in, Salmonella induced cytotoxicity on and ROS production by macrophages. The Salmonella invasion capacity of the tested Salmonella strains did not significantly differ, except for strain MB2498 that was significantly impaired in infecting macrophages. This might be due to the fact that this strain was markedly less motile than the other strains, as assessed by growing the strains in semi solid agar $[48,49]$. Infection with all tested Salmonella strains was cytotoxic for macrophages $24 \mathrm{~h}$ pi. Finally, the macrophage activation status indicated by ROS production measurement did not differ between Salmonella strains. Because we found no significant correlation between the extent of MHC II downregulation on one hand, and Salmonella invasiveness, cytotoxicity or induction of ROS production on the other hand, we can conclude that strain specific differences in the capacity to downregulate MHC II expression on porcine macrophages are irrespective of strain specific differences in invasion capacity and cytotoxic effects on or induction of ROS production by macrophages.

Since we showed that SPI-1 and SPI-2 are involved in Salmonella Typhimurium strain 112910a induced downregulation of MHC II expression, we wanted to examine if differential SPI-1 and/or SPI-2 gene expression accounted for the observed differences in MHC II downregulation between Salmonella strains. Surprisingly, no correlation was found between the expression of SPI-1 genes hilA and sopB for a certain strain, although this can be due to the fact that expression of the effector protein SopB is only partly regulated by HilA [22]. Furthermore, no $\operatorname{sopB}$ expression was detected in Salmonella MB2498 and Derby strains, indicating the absence of the $\operatorname{sop} B$ containing SPI-5 in these strains $[13,50]$. Expression of SPI-2 genes $s s r A / B$ and $s s a H$ 
markedly differed between Salmonella strains, and in contrast to hilA and $\operatorname{sop} B$ expression, a significantly positive correlation was found between $s s r A / B$ and $s s a H$ expression in a certain strain. However, no correlation was found between SPI-1 or SPI-2 gene expression and the capacity to downregulate MHC II expression. Although Salmonella gene expression in LB medium and inside macrophages might vary, the fact that SPI-1 and SPI-2 gene expression patterns of different Salmonella strains did not correlate with their capacity to interfere with the MHC II expression level of macrophages might indicate that other factors than SPI-1 and SPI-2 are also involved in Salmonella induced $\mathrm{MHC}$ II downregulation.

In conclusion, we showed that Salmonella Typhimurium strain 112910a specifically downregulated MHC II expression on porcine macrophages in merely a SPI-1 and SPI-2 dependent way. Furthermore, opsonization of Salmonella with antibodies counterbalanced the bacterium's capacity to downregulate MHC II expression and to proliferate intracellularly, emphasizing the importance for Salmonella to interfere with the host's immune response for successful persistence. The extent of MHC II downregulation on macrophages differed among Salmonella strains and these strain specific differences did not correlate with differential SPI-1 and/or SPI-2 expression, providing evidence that besides SPI-1 and SPI- 2 other factors are also involved in Salmonella induced downregulation of MHC II expression. Our findings might imply that Salmonella strains that are capable of circumventing the pig's immune response can better persist in pigs, interfering with serological screenings that are used in most preharvest Salmonella monitoring programs in Europe to date.

\section{Competing interests}

Sources of financial support have been acknowledged and the authors declare that they have no competing interests.

\section{Acknowledgements}

The technical assistance of Rosalie Devloo and Nathalie Vanrysselberghe is greatly appreciated. This work was supported by the Institute for the Promotion of Innovation by Science and Technology in Flanders (IWT Vlaanderen), Brussels, Belgium (grant IWT Landbouw 040791) and the Research Foundation Flanders (FWO)

\section{Authors' contributions}

$A V P, F B, F P$ and $F H$ participated in the design of the study. AVP, BF, EV and $B L$ performed the experiments and AVP and BF analysed the data. AVP, FP, $\mathrm{FB}$ and $\mathrm{FH}$ wrote the manuscript. All authors read and approved the final manuscript.

Received: 30 December 2011 Accepted: 13 June 2012 Published: 13 June 2012

\section{References}

1. Majowicz SE, Musto J, Scallan E, Angulo FJ, Kirk M, O'Brien SJ, Jones TF, Fazil A, Hoekstra RM: The global burden of nontyphoidal Salmonella gastroenteritis. Clin Infect Dis 2010, 50:882-889.

2. Anonymous: Report of the task force on zoonoses data collection on the analysis of the baseline survey on the prevalence of Salmonella in slaughter pigs, in the EU, 2006-2007. Part A: Salmonella prevalence estimates. EFSA J 2008, 135:1-111.
3. Botteldoorn N, Heyndrickx M, Rijpens N, Grijspeerdt K, Herman L: Salmonella on pig carcasses: positive pigs and cross contamination in the slaughterhouse. J Appl Microbiol 2003, 95:891-903.

4. Wood RL, Pospischil A, Rose R: Distribution of persistent Salmonella Typhimurium infection in internal organs of pigs. Am J Vet Res 1989, 50:1015-1021.

5. Boyen F, Haesebrouck F, Maes D, Van Immerseel F, Ducatelle R, Pasmans F: Non-typhoidal Salmonella infections in pigs: a closer look at epidemiology, pathogenesis and control. Vet Microbiol 2008, 130:1-19.

6. Proux K, Houdayer C, Humbert F, Cariolet R, Rose V, Eveno E, Madec F: Development of a complete ELISA using Salmonella lipopolysaccharides of various serogroups allowing to detect al infected pigs. Vet Res 2000, 31:481-490.

7. Nielsen B, Baggesen D, Bager F, Haugegaard J, Lind P: The serological response to Salmonella serovars Typhimurium and Infantis in experimentally infected pigs, The time course followed with an indirect anti-LPS ELISA and bacteriological examinations. Vet Microbiol 1995, 47:205-218

8. Srinand S: Serologic studies of experimentally induced Salmonella choleraesuis var kunzendorf infection in pigs. Am J Vet Res 1995, 56:1163-1168.

9. Van Winsen RL, van Nes A, Keuzenkamp D, Urlings HAP, Lipman LJA Biesterveld S, Snijders JMA, Verheijden JHM, van Knapen F: Monitoring of transmission of Salmonella enterica serovars in pigs using bacteriological and serological detection methods. Vet Microbiol 2001, 80:267-274.

10. Hornef WH, Wick MJ, Rhen M, Normark S: Bacterial strategies for overcoming host innate and adaptive immune responses. Nat Immunol 2002, 3:1033-1040

11. Hegde NR, Chevalier MS, Johnson DC: Viral inhibition of MHC class II antigen presentation. Trends Immunol 2003, 24:278-285.

12. Mitchell EK, Mastroeni P, Kelly AP, Trowsdale J: Inhibition of cell surface MHC class II expression by Salmonella. Eur J Immunol 2004, 434:2559-2567.

13. Blondel CJ, Jiménez JC, Contreras I, Santiviago CA: Comparative genomic analysis uncovers 3 novel loci encoding type six secretion systems differentially distributed in Salmonella serotypes. BMC Genomics 2009, 10:354.

14. Fink SL, Cookson BT: Pyroptosis and host cell death responses during Salmonella infection. Cell Microbiol 2007, 9:2562-2570.

15. Donné E, Pasmans F, Boyen F, Van Immerseel F, Adriaensen C, Hernalsteens J-P, Ducatelle R, Haesebrouck F: Survival of Salmonella serovar Typhimurium inside porcine monocytes is associated with complement binding and suppression of the production of reactive oxygen species. Vet Microbiol 2005, 107:205-214.

16. Jantsch J, Chikkaballi D, Hensel M: Cellular aspects of immunity to intracellular Salmonella enterica. Immunol Rev 2011, 240:185-195.

17. Boyen F, Pasmans F, Van Immerseel F, Donné E, Morgan E, Ducatelle R, Haesebrouck F: Porcine in vitro and in vivo models to assess the virulence of Salmonella enterica serovar Typhimurium for pigs. Lab Anim 2009, 43:46-52.

18. Van Parys A, Boyen F, Volf J, Verbrugghe E, Leyman B, Rychlik I, Haesebrouck F, Pasmans F: Salmonella Typhimurium resides largely as an extracellular pathogen in porcine tonsils, independently of biofilm-associated genes $\operatorname{csg} A, \operatorname{csg} D$ and adrA. Vet Microbiol 2010, 144:93-99.

19. Datsenko KA, Wanner BL: One-step inactivation of chromosomal genes in Escherichia coli K-12 using PCR products. Proc Natl Acad Sci U S A 2000 97:6640-6645

20. Boyen F, Pasmans F, Donné E, Van Immerseel F, Adriaensen C, Hernalsteens JP, Ducatelle R, Haesebrouck F: Role of SPI-1 in the interactions of Salmonella Typhimurium with porcine macrophages. Vet Microbiol 2006, 113:35-44.

21. Boyen F, Pasmans F, Van Immerseel F, Morgan E, Botteldoorn N, Heyndrickx M, Volf J, Favoreel H, Hernalsteens JP, Ducatelle R, Haesebrouck F: A limited role for SsrA/B in persistent Salmonella Typhimurium infections in pigs. Vet Microbiol 2008, 128:364-373.

22. Thijs IMV, De Keersmaecker SCJ, Fadda A, Engelen $\mathrm{K}$, Zhao H, McClelland M, Marchal K, Vanderleyden J: Delineation of the Salmonella enterica serovar Typhimurium HilA regulon through genome-wide location and transcript analysis. J Bacteriol 2007, 189:4587-4596.

23. Carroll RK, Liao X, Morgan LK, Cicirelli EM, Li Y, Sheng W, Feng X, Kenney LJ: Structural and functional analysis of the C-terminal DNA binding domain of the Salmonella Typhimurium SPI-2 response regulator SsrB. J Biol Chem 2009, 284:12008-12019. 
24. Leemans J, Langenakens J, Degreve H, Deblaere R, Vanmontagu M, Schell J: Broad-host-range cloning vectors derived from the W-plasmid Sa. Gene 1982, 19:361-364.

25. Pasmans F, Van Immerseel F, Heyndrickx M, Martel A, Godard C, Wildemauwe C, Ducatelle R, Haesebrouck F: Host adaptation of pigeon isolates of Salmonella enterica subsp enterica serovar Typhimurium variant Copenhagen phage type 99 is associated with enhanced macrophage cytotoxicity. Infect Immun 2003, 71:6068-6074.

26. Van Immerseel F, De Buck J, De Smet I, Mast J, Haesebrouck F, Ducatelle R: Dynamics of immune cell infiltration in the caecal lamina propria of chickens after neonatal infection with a Salmonella Enteritidis strain. Dev Comp Immunol 2002, 26:355-364

27. Vangroenweghe F, Duchateau L, Burvenich C: Moderate inflammatory reaction during experimental Escherichia coli mastitis in primiparous cows. J Dairy Sci 2004, 87:886-895.

28. Valdivia $\mathrm{RH}$, Falkow S: Bacterial genetics by flow cytometry: rapid isolation of Salmonella Typhimurium acid-inducible promoters by differential fluorescence induction. Mol Microbiol 1996, 22:367-378.

29. Dom P, Haesebrouck F, Debaetselier P: Chemiluminescence properties of porcine pulmonary alveolar macrophages and polymorphonuclear cells. Vet Quart 1994, 16:87-90.

30. Bekay RE, Álvarez M, Carballo M, Martín-Nieto J, Monteseirín J, Pintado E, Bedoya FJ, Sobrino F: Activation of phagocytic cell NADPH oxidase by norfloxacin: a potential mechanism to explain its bactericidal action. $J$ Leukocyte Biol 2002, 71:255-261.

31. Rychlik I, Martin G, Methner U, Lovell M, Cardova L, Sebkova A, Sevcik M, Damborsky J, Barrow PA: Identification of Salmonella enterica serovar Typhimurium genes associated with growth suppression in stationary-phase nutrient broth cultures and in the chicken intestine. Arch Microbiol 2002, 178:411-420.

32. Van Immerseel F, De Buck J, Boyen F, Bohez L, Pasmans F, Volf J, Sevcik M, Rychlik I, Haesebrouck F, Ducatelle R: Medium-chain fatty acids decrease colonization and invasion through hilA suppression shortly after infection of chickens with Salmonella enterica serovar Enteritidis. Appl Environ Microb 2004, 70:3582-3587.

33. Österberg J, Wallgren P: Effects of a challenge dose of Salmonella Typhimurium or Salmonella Yoruba on the patterns of excretion and antibody responses of pigs. Vet Rec 2008, 162:580-586.

34. Scherer K, Szabo I, Rösler U, Appel B, Hensel A, Nöckler K: Time course of infection with Salmonella Typhimurium and its influence on fecal shedding, distribution in inner organs, and antibody response in fattening pigs. J Food Protect 2008, 71:699-705.

35. Villadangos JA: Presentation of antigens by MHC class II molecules: getting the most out of them. Mol Immunol 2001, 38:329-346.

36. Knodler LA, Steele-Mortimer O: Taking possession: biogenesis of the Salmonella-containing vacuole. Traffic 2003, 4:587-599.

37. Janeway CA, Travers P, Walport M, Schlomchik MJ: Macrophages are scavenger cells that can be induced by pathogens to present foreign antigens to naïve T cells. In Immunobiology: the immune system in health and disease. 6th edition. Edited by Lawrence E. New York: Garland Science Publishing; 2005:334-335.

38. Norimatsu M, Harris J, Chance V, Dougan G, Howard CJ, Villarreal-Ramos B: Differential response of bovine monocyte-derived macrophages and dendritic cells to infection with Salmonella Typhimurium in a low-dose model in vitro. Immunology 2003, 108:55-61.

39. Boyen F, Pasmans F, Van Immerseel F, Morgan E, Adriaensen C, Hernalsteens JP, Decostere A, Ducatelle R, Haesebrouck F: Salmonella Typhimurium SPI-1 genes promote intestinal but not tonsillar colonization in pigs. Vet Microbiol 2006, 8:2899-2907.

40. Troxell B, Sikes M, Fink R, Vazquez-Torres A, Jones-Carson J, Hassan H: Fur negatively regulates $h n s$ and is required for the expression of $h i l A$ and virulence in Salmonella enterica serovar Typhimurium. J Bacteriol 2011, 193:497-505.

41. Casadevall A: Antibody-mediated protection against intracellular pathogens. Trends Microbiol 1998, 6:102-107.

42. Drecktrah D, Knodler LA, Ireland R, Steele-Mortimer O: The mechanism of Salmonella entry determines the vacuolar environment and intracellular gene expression. Traffic 2006, 7:39-51.

43. Lim S, Yong K, Ryu S: Analysis of Salmonella pathogenicity island 1 expression in response to the changes of osmolarity. J Microbiol Biotechn 2005, 15:175-182.
44. Yu XY, McGourty K, Liu M, Unsworth KE, Holden DW: pH sensing by intracellular Salmonella induces effector translocation. Science 2010, 328:1040-1043.

45. Rodrigues APD, Carvalho ASC, Santos AS, Alves CN, Do Nascimento JLM, Silva EOS: Kojic acid, a secondary metabolite from Aspergillus sp., acts as an inducer of macrophage activation. Cell Biol Int 2011, 35:335-343.

46. Volf J, Havlickova H, Hradecka H, Ondrackova P, Matiasovic J, Faldyna M, Rychlik I: Epidemiology and interaction of Salmonella enterica serovar Derby, Infantis and Typhimurium with porcine alveolar macrophages. Vet Microbiol 2010, 146:105-110.

47. Bearson BL, Bearson SMD: Host specific differences alter the requirement for certain Salmonella genes during swine colonization. Vet Microbiol 2011, 150:215-219.

48. Moreira CG, Weinshenker D, Sperandio V: QseC mediates Salmonella enterica serovar Typhimurium virulence in vitro and in vivo. Infect Immun 2010, 78:914-926.

49. Shah DH, Zhou X, Addwebi T, Davis MA, Orfe L, Call DR, Guard J, Besser TE: Cell invasion of poultry-associated Salmonella enterica serovar Enteritidis isolates is associated with pathogenicity, motility and proteins secreted by the type III secretion system. Microbiology 2011, 157:1428-1445.

50. Wood MW, Jones MA, Watson PR, Hedges S, Wallis TS, Galyov EE: Identification of a pathogenicity island required for Salmonella enteropathogenicity. Mol Microbiol 1998, 29:883-891.

doi:10.1186/1297-9716-43-52

Cite this article as: Van Parys et al: Salmonella Typhimurium induces SPI-1 and SPI-2 regulated and strain dependent downregulation of MHC II expression on porcine alveolar macrophages. Veterinary Research 2012 43:52.

\section{Submit your next manuscript to BioMed Central and take full advantage of:}

- Convenient online submission

- Thorough peer review

- No space constraints or color figure charges

- Immediate publication on acceptance

- Inclusion in PubMed, CAS, Scopus and Google Scholar

- Research which is freely available for redistribution 